\title{
Effect of Parameters in the Physical Simulated Rough Rolling Stage on Microstructure Evaluation and Tensile Properties of a Bainitic Pipeline Steel
}

\author{
Mohamed Soliman ${ }^{1, a^{*}}$, Heinz Palkowski ${ }^{1, b}$ \\ ${ }^{1}$ Institute of Metallurgy, Clausthal University of Technology, Robert-Koch-Straße 42, 38678 \\ Clausthal-Zellerfeld, Germany \\ amohamed.soliman@tu-clausthal.de, ${ }^{\mathrm{b}}$ heinz.palkowski@tu-clausthal.de
}

Keywords: Bainitic pipeline steel; hot working parameters; thermo-mechanical simulation; microstructure evolution.

\begin{abstract}
Microstructure evolution and tensile properties were studied in a bainitic pipeline steel grade by performing a number of physical simulations on samples machined out of an industrially produced transfer bar. In these simulations, the cooling interval between roughing and finishing stages $\left(t_{V}\right)$ was varied from $5 \mathrm{~s}$ to $180 \mathrm{~s}$. The austenite status after this cooling interval, regarding the prior austenite grain size and precipitates, simulates the condition of austenite before entering the finishing mill. The finishing parameters and the subsequent cooling strategy were kept unchanged throughout all the applied simulation processes. The gradual increase in $t_{V}$ resulted in a gradual increase of the granular bainite phase on the expense of the aciculare ferrite. This resulted in an incremental decrease in ultimate tensile strength and yield strength with increasing $\mathrm{t}_{\mathrm{V}}$. However, this behavior approached a steady state condition after which the $t_{V}$ has limited/insignificant effect on the ultimate- and yield strength. This saturating value of $t_{V}$ is process parameter dependent.
\end{abstract}

\section{Introduction}

The demand of the pipeline industry for a more cost-effective pipeline design has pushed the standard pipeline steel grade requirements. Critical to the design of these steels is a low carbon equivalent for good field weldability [1,2]. In these steels, the carbon is reduced to below 0.09 wt.\%. The strength loss due to the low $\mathrm{C}$ content is compensated through alloy design philosophy based on the advanced use of cost effective micro-alloying elements, such as $\mathrm{Nb}$, Ti and $\mathrm{B}$ in conjunction with moderate levels of other alloying elements, such as $\mathrm{Mn}, \mathrm{Si}, \mathrm{Cr}, \mathrm{Mo}$ and $\mathrm{Cu}$ [3]. The use of aforementioned combinations of micro-alloying and alloying elements in conjunction with thermo-mechanical controlled processing (TMCP) lead to the development of API $\mathrm{X} 80, \mathrm{X} 100$ and X120 which exhibit yield strengths from $550 \mathrm{MPa}$ up to $825 \mathrm{MPa}$ [4]. In these steels, the desired balance of mechanical properties at a given steel composition are achieved through suitably designed thermo-mechanical processing schedules [5], which commonly involve controlled rolling, followed by controlled accelerated cooling. The controlled rolling compresses two stages, namely roughing and finishing rolling. Roughing starts after the austenitization process. During the rough rolling the austenite grain size is refined due to repeated cycles of work hardening and the recrystallization process. The finishing rolling starts subsequent to the roughing. During the finishing rolling the austenite is deformed in the non-recrystallization temperature regime, which brings significant refinement to the final microstructure. The accelerated cooling step aims to suppress the formation of polygonal ferrite and, instead, encourage non-equilibrium, non-equiaxed ferrite microstructures to be formed. The latter transformation products are known to contribute to increasing strength, through both small effective grain sizes and increased dislocation densities, while maintaining a reasonable level of toughness $[1,5,6]$.

Objective. It was shown in [7] that decreasing the delay-time between the roughing and finishing rolling stages $\left(t_{V}\right)$ from $180 \mathrm{~s}$ to $5 \mathrm{~s}$ resulted in pronounced improvement in both of ultimate tensile strength and proof stress. During the current work the same steel is processed under the same 
thermo-mechanical (TM) processing parameters except that and intermediate values of $t_{V}$ between $5 \mathrm{~s}$ and $180 \mathrm{~s}$ are selected. The effect of the cooling time on the microstructure development and the mechanical properties is investigated.

\section{Experimental Procedure}

Material and Specimens Preparation. The current study is carried out on samples machined out of a transfer bar of API X80 pipeline steel. Salzgitter Flachstahl GmbH is acknowledged for providing the raw material. The chemical composition of the studied material is given in Table 1.

Table 1. Chemical analysis of the studied material (wt. \%)

\begin{tabular}{|c|c|c|c|c|c|c|c|c|c|}
\hline $\mathrm{C}$ & $\mathrm{Si}$ & $\mathrm{Mn}$ & $\mathrm{P}$ & $\mathrm{N}$ & $\mathrm{Cr}$ & $\mathrm{Mo}$ & $\mathrm{Ti}$ & $\mathrm{Nb}$ & $\mathrm{S}$ \\
\hline 0.055 & 0.3 & 1.84 & 0.014 & 0.006 & 0.18 & 0.259 & 0.0256 & 0.101 & 0.0008 \\
\hline
\end{tabular}

The provided steel slab has a thickness of $52 \mathrm{~mm}$. All the specimens were taken with their longitudinal axes parallel to the rolling direction of the transfer bar and their thicknesses parallel to its thickness. The thickness-center region is excepted during machining of the specimens that is to avoid the zone of central segregation of the slab. The dimensions of the flat compression samples are shown in Fig. 1. The thickness of the specimen in the testing-zone is $6.4 \mathrm{~mm}$. The specimen has $42 \mathrm{~mm}$ shoulders for clamping in the tensile testing machine after thermomechanical processing. The two $\varnothing 6 \mathrm{~mm}$ holes are for reducing the heat dissipation from the testing- zone to the shoulders. All the simulation specimens are taken with their longitudinal axes parallel to the rolling direction and their thicknesses parallel to the thickness of the transfer bar.

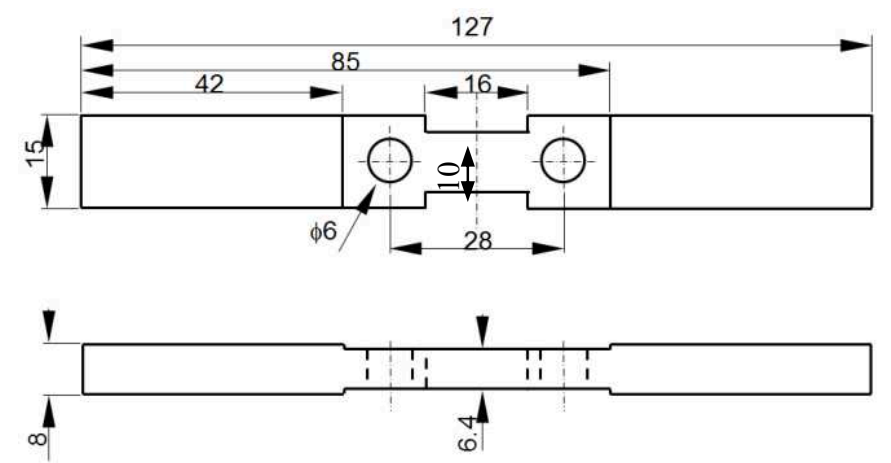

Fig. 1. Dimensions of the flat compressing sample

TM simulator TTS 820 is used for carrying out the simulation process. For this purpose, a thermocouple is spot welded on the specimen, and then the specimen is placed on two ceramic rollers and fixed from the upper side by two ceramic rods. Two deformation stamps upset the specimen in its center. A detailed description of the flat compression setup of TTS 820 is given in [7].

Thermo-mechanical Simulation. The samples with a geometry shown in Fig. 1 are subjected to the TM schedule sketched in Fig. 2. In this schedule, specimens were heated up to the austenitization temperature $\left(\mathrm{T}_{\mathrm{A}}\right)$ and subjected to one deformation step with a true strain value of $\varphi_{\mathrm{v}}$ at $\mathrm{T}_{\mathrm{V}}$. The austenite status at this stage - regarding the prior austenite grain size (PAGS) and precipitation - simulates the condition of austenite after the roughing process. The subsequent three deformation steps are to simulate the finishing rolling process, the time between roughing and finishing is designated in the figure by $t_{\mathrm{V}}$. The studied parameters are varied according to the values listed in Table 2. The finishing rolling parameters and the subsequent cooling strategy were kept unchanged throughout all the applied simulation processes. The parameters in Table 2 are considered for varying the austenite status before entering the finishing mill. Two values of $t_{V}$ were 
investigated in reference [7], namely $5 \mathrm{~s}$ and $180 \mathrm{~s}$. The results of this project showed a strong dependence of the ultimate and proof strength on $t_{\mathrm{V}}$. During the current study, additional intermediate values for $t_{V}$ were investigated, written in italic font-style in Table 2.

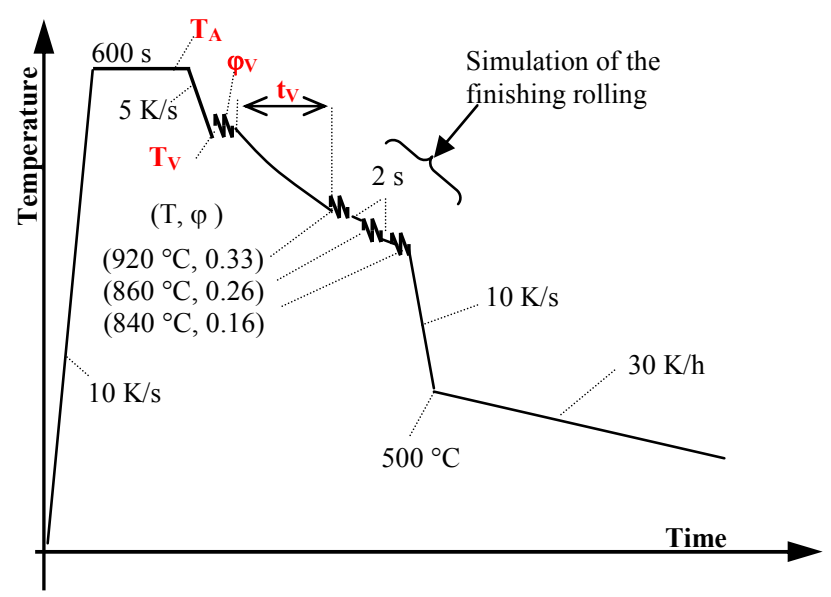

Fig. 2. Schematic drawing of the applied thermo-mechanical schedule.

Table 2. Combination of parameters studied (Fig. 2)

\begin{tabular}{|c|c|c|c|c|c|c|c|c|c|c|c|c|c|c|c|c|c|c|c|c|}
\hline $\mathrm{T}_{\mathrm{A}}\left({ }^{\circ} \mathrm{C}\right)$ & \multicolumn{14}{|c|}{1285} & \multirow{2}{*}{\multicolumn{6}{|c|}{$\begin{array}{l}1185 \\
1000\end{array}$}} \\
\hline $\mathrm{T}_{\mathrm{V}}\left({ }^{\circ} \mathrm{C}\right)$ & \multicolumn{8}{|c|}{1000} & \multicolumn{6}{|c|}{1100} & & & & & & \\
\hline$\varphi_{\mathrm{V}}(-)$ & \multicolumn{5}{|c|}{0.3} & \multicolumn{3}{|c|}{0.5} & \multicolumn{3}{|c|}{0.3} & \multicolumn{3}{|c|}{0.5} & \multicolumn{3}{|c|}{0.3} & \multicolumn{3}{|c|}{0.5} \\
\hline $\mathrm{t}_{\mathrm{V}}(\mathrm{s})$ & 5 & 30 & 60 & 120 & 180 & 5 & 60 & 180 & 5 & 60 & 180 & 5 & 60 & 180 & 5 & 60 & 180 & 5 & 60 & 180 \\
\hline
\end{tabular}

Light Optical Microscopy. Light optical microscopic (LOM) analysis of the as-received samples as well as samples from various processing and conditions was performed by sectioning the samples parallel to the deformation direction, and cold mounting. The samples were rough polished using standard metallographic abrasive grinding papers ranging from coarse (180) to fine (1200). The final polishing was done using $1.0 \mu \mathrm{m}$ and $0.05 \mu \mathrm{m}$ alumina, respectively. After polishing, the samples were rinsed with ethyl alcohol and dried. The microstructure was developed by etching with $2 \%$ Nital.

Tensile Testing. The tensile tests were conducted in a computerized universal testing machine (UTS) with a $250 \mathrm{kN}$ load cell using a crosshead speed of $5 \mathrm{~mm} / \mathrm{min}$.

\section{Results and Discussion}

Microstructure Evolution. Metallographic investigations using LOM were conducted to investigate the effect of $t_{\mathrm{V}}$ on the microstructure development.

$\mathbf{T}_{\mathbf{A}}=1250{ }^{\circ} \mathbf{C}-\mathbf{T}_{\mathbf{V}}=1000{ }^{\circ} \mathbf{C}-\varphi_{\mathbf{V}}=\mathbf{0 . 3}$. The effects of $t_{V}$ on the microstructure for the samples austenitized at $\mathrm{T}_{\mathrm{A}}=1250{ }^{\circ} \mathrm{C}$ and deformed at $\mathrm{T}_{\mathrm{V}}=1000{ }^{\circ} \mathrm{C}$ with $\varphi_{\mathrm{V}}=0.3$ is shown in Fig. 3. The micrographs of Fig. 3 show that the $(\mathrm{Nb}, \mathrm{Ti})(\mathrm{C}, \mathrm{N})$ precipitates are well distributed in all microstructures. The composition of these precipitates was investigated by using energy dispersive X-ray spectroscopy (EDX) [7]. TiN precipitates form at higher temperature in the austenite region. These precipitates serve as "cores" for the nucleation and epitaxial growth at lower temperatures of shell of $\mathrm{NbCN}$ [8]. The obtained precipitates have an average size of about $132 \mathrm{~nm}$. The addition of $\mathrm{Nb}$ and $\mathrm{Ti}$ to pipeline steels effectively refines the austenite grain during the hot-rolling process because the precipitates retard austenite recrystallization and, in turn, refine the final microstructure. This microstructure refinement together with the existence of nano-size phase, which is the 
precipitates themselves result in enhancing the mechanical properties of the pipeline steel. The microstructure is predominantly a mixture of acicular ferrite (AF) and granular bainite (GB). The microstructures for the samples having $t_{V}=180 \mathrm{~s}$ (Fig. 3e) is dominated by the GB structure. For $t_{V}=5 \mathrm{~s}$ (Fig. 3a), the microstructures show more AF and finer GB than that obtained for $t_{V}=180 \mathrm{~s}$. The domination of the GB structure is also observed in the microstructures of the samples with $t_{\mathrm{V}}=60 \mathrm{~s}$ and $120 \mathrm{~s}$. The sample with $t_{\mathrm{V}}=30 \mathrm{~s}$ shows more or less similar microstructural features to that for $t_{\mathrm{V}}=5 \mathrm{~s}$. The very tiny phase, e.g. the encircled phase in Fig. 3, is defined as a martensite/austenite (M/A) phase; this is confirmed by scanning electron microscopic investigations as shown in [7]. The occurrence of tiny martensite/austenite (M/A) phase is more pronounced for $t_{V}=5 \mathrm{~s}$ and $30 \mathrm{~s}$ than for $\mathrm{t}_{\mathrm{V}}=60 \mathrm{~s}, 120 \mathrm{~s}$ and $180 \mathrm{~s}$. The shorter cooling time between the roughing and finishing resulted in finer and/or pancaked prior austenite grains which motivated the formation of both, $\mathrm{AF}$ and fine $\mathrm{M} / \mathrm{A}$ phases.

$\mathbf{T}_{\mathbf{A}}=1150{ }^{\circ} \mathbf{C}-\mathbf{T}_{\mathbf{V}}=1000{ }^{\circ} \mathbf{C}-\varphi_{\mathbf{V}}=\mathbf{0 . 3}$. A similar effect of $t_{V}$ on the phase distribution of AF and GB in the samples with $\mathrm{T}_{\mathrm{A}}=1250{ }^{\circ} \mathrm{C}$ is observed in samples with $\mathrm{T}_{\mathrm{A}}=1150{ }^{\circ} \mathrm{C}$ (see Fig. 4). Explicitly, increasing $t_{\mathrm{V}}$ to $180 \mathrm{~s}$ resulted in the domination of the GB phase. Furthermore, for $t_{V}=60 \mathrm{~s}$, the samples showed similar features compared to samples with $t_{\mathrm{V}}=180 \mathrm{~s}$ rather than to that with $\mathrm{t}_{\mathrm{V}}=5 \mathrm{~s}$.
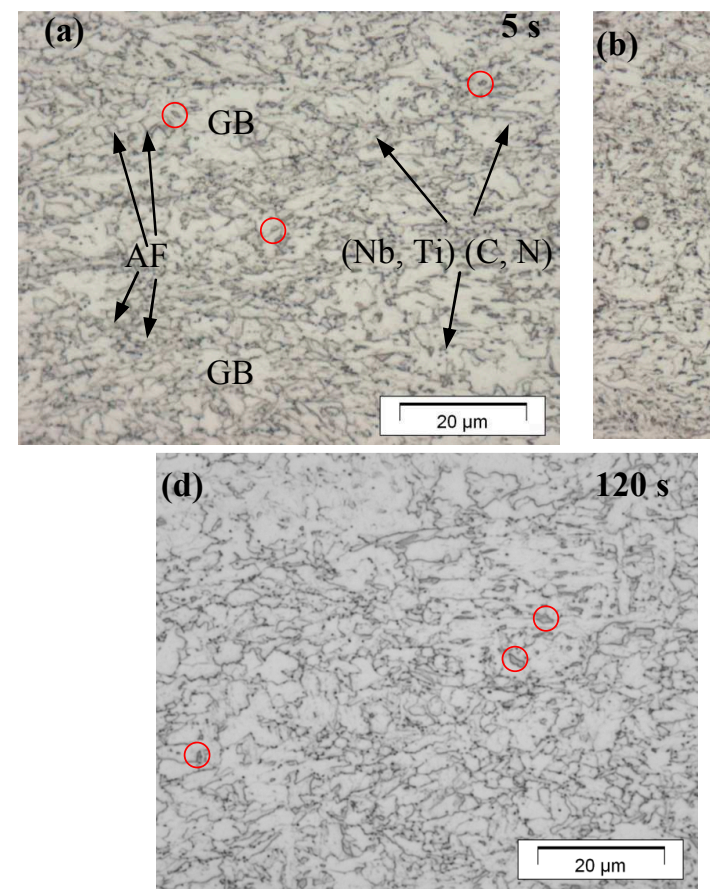
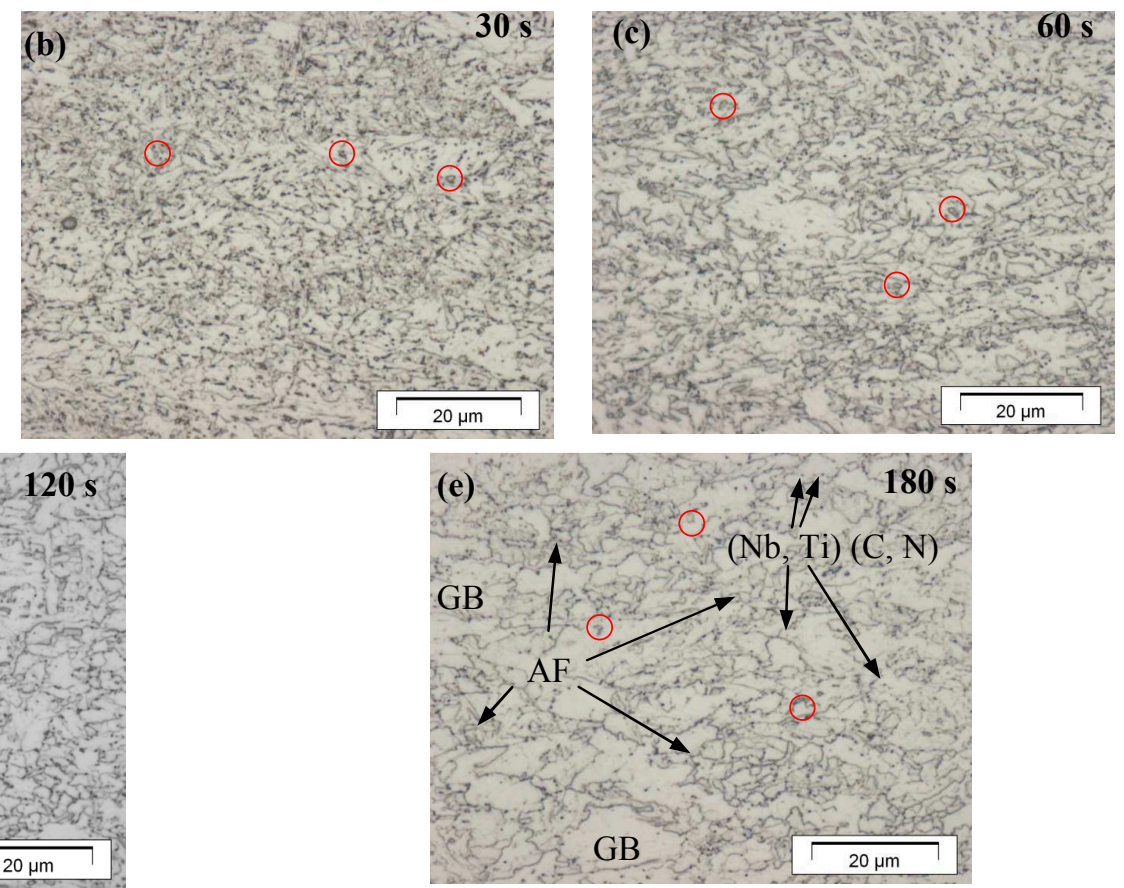

Fig. 3. Effect of $t_{V}$ on the microstructure for samples austenitized at $\mathrm{T}_{\mathrm{A}}=1250{ }^{\circ} \mathrm{C}$ and deformed at $\mathrm{T}_{\mathrm{V}}$ with $\varphi_{\mathrm{V}}=0.3$. Etchant: Nital.
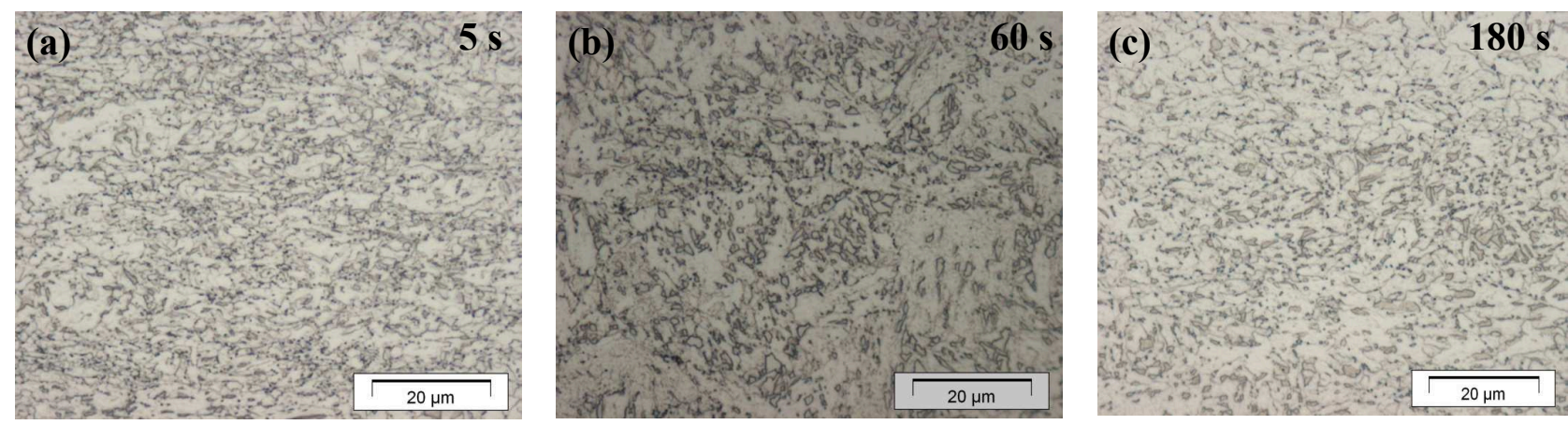

Fig. 4. Effect of $t_{\mathrm{V}}$ on the microstructure for the samples austenitised at $\mathrm{T}_{\mathrm{A}}=1150{ }^{\circ} \mathrm{C}$ and deformed at $\mathrm{T}_{\mathrm{V}}=1000{ }^{\circ} \mathrm{C}$ with $\varphi_{\mathrm{V}}=0.3$. Etchant: Nital. 
Mechanical Properties. Fig. 5 shows the effect of $t_{V}$ on the stress-strain curves for different TM treatment conditions. The incremental increase in $t_{V}$ generally results in an incremental decrease in ultimate tensile strength $\left(\mathrm{R}_{\mathrm{m}}\right)$ and yield strength $\left(\mathrm{R}_{\mathrm{p}}\right)$. e.g. $840 \mathrm{MPa}$ was the highest recorded $\mathrm{R}_{\mathrm{m}}$ value of the steel with $\mathrm{T}_{\mathrm{A}}=1250{ }^{\circ} \mathrm{C}-\mathrm{T}_{\mathrm{V}}=1000{ }^{\circ} \mathrm{C}-\varphi_{\mathrm{V}}=0.5$ when $_{\mathrm{V}}=5 \mathrm{~s}$. The lowest $\mathrm{R}_{\mathrm{m}}$ value of $692 \mathrm{MPa}$ was recorded for the same condition but with $t_{\mathrm{V}}=180 \mathrm{~s}$. However, it seems that this behavior has a saturation point after which $t_{V}$ has a limited/insignificant effect on $R_{m}$ and $R_{p}$. The saturation point for large prior austenite grains $\left(\mathrm{T}_{\mathrm{A}}=1250{ }^{\circ} \mathrm{C}\right)$ deformed at a low temperature $\left(\mathrm{T}_{\mathrm{V}}=1000{ }^{\circ} \mathrm{C}\right)$ is not reached at $t_{\mathrm{V}}=60 \mathrm{~s}$ (Fig. 5a and 5b) but rather at $t_{\mathrm{V}}=120 \mathrm{~s}$ (Fig. 5a). On the other hand, a value of $60 \mathrm{~s}$ for $\mathrm{t}_{\mathrm{V}}$ was enough to attain the saturation point for large prior austenite grains deformed at high temperature (Fig. $5 \mathrm{~b}$ and $5 \mathrm{e}$ ). For smaller PAG $\left(\mathrm{T}_{\mathrm{A}}=1150{ }^{\circ} \mathrm{C}\right), \varphi_{\mathrm{V}}$ is deceive for the saturating $t_{\mathrm{V}}$; for $\varphi_{\mathrm{V}}=0.3 \mathrm{a} t_{\mathrm{V}}$ of $60 \mathrm{~s}$ was enough for attaining saturation in $\mathrm{R}_{\mathrm{m}}$ and $R_{p}$ values (Fig. 5c). Higher $t_{V}$ is required to attain this saturation for $\varphi_{V}=0.5$ (Fig. 5f).

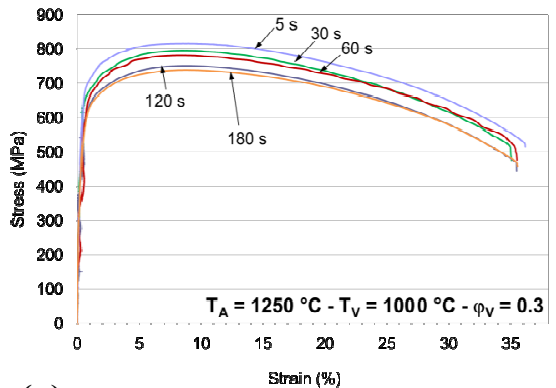

(a)

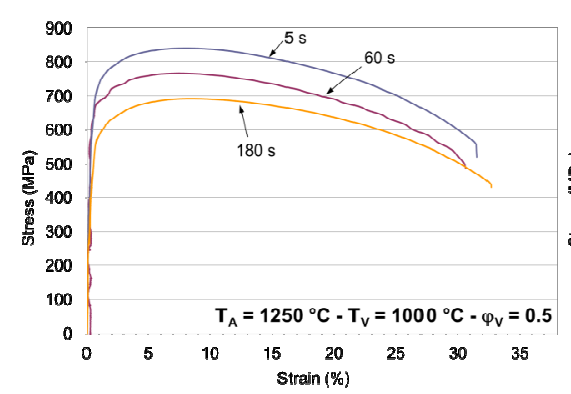

(d)

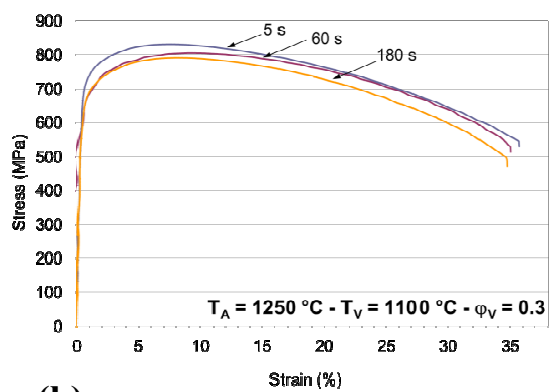

(b)

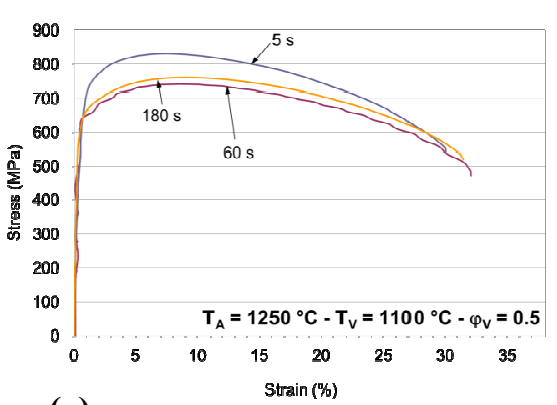

(e)

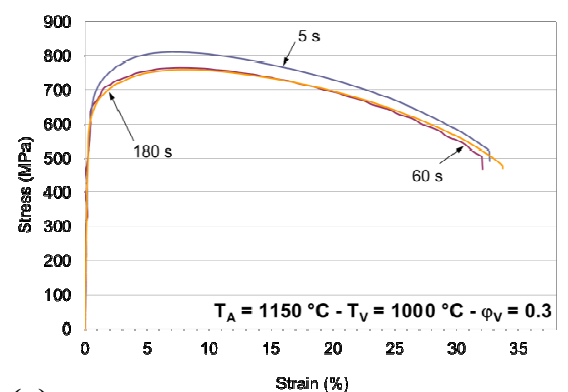

(c)

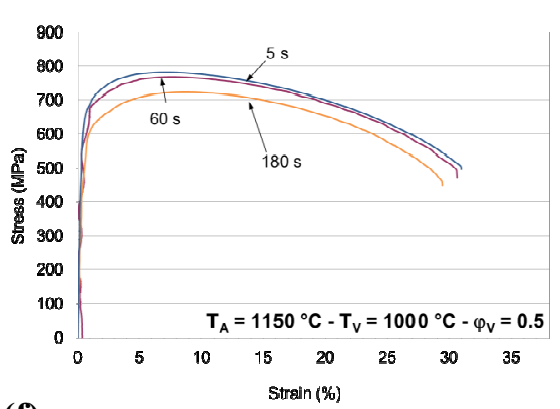

(f)

Fig. 5 Stress-strain curves of samples processed under the prescribed TM treatment conditions.

\section{Summary}

Microstructure evolution and tensile properties were studied in a pipeline steel grade API-X80 by performing a number of physical simulations on samples machined out of an industrially produced transfer bar.

In this physical simulation, specimens were heated up to the austenitization temperature $\left(\mathrm{T}_{\mathrm{A}}\right)$ and subjected to one deformation step having a true strain value of $\varphi_{\mathrm{V}}$ at $\mathrm{T}_{\mathrm{V}}$. The cooling interval between roughing and finishing is designated by $\left(t_{\mathrm{V}}\right)$. The austenite status after this cooling interval, regarding the prior austenite grain size (PAGS) and precipitates simulates the condition of austenite before entering the finishing mill. The finishing parameters and the subsequent cooling strategy were kept unchanged throughout all the applied simulation processes. The results showed a strong dependence of the $R_{m}$ and $R_{p}$ on $t_{V}$. The gradual increase in $t_{V}$ results in a gradual increase of the granular bainite phase on the expense of the aciculare ferrite. This results in an incremental decrease in $R_{m}$ and $R_{p}$ with increasing $t_{V}$. However, it seems that this behavior has a saturation point after which the $t_{V}$ has a limited/insignificant effect on the $R_{m}$ and $R_{p}$. This saturating value of $t_{V}$ is process parameter dependent. 


\section{References}

[1] J.G. Williams, C.R. Killmore, F.J. Barbaro, A. Meta, L. Fletcher, Modern technology for ERW linepipe steel production (X60 to X80 and beyond), Proc. Int. Conf. Microalloying 95. Warrendale, USA (1995) 117-139.

[2] P. Cizek, Transformation behaviour and microstructure of an API x80 line-pipe steel subjected to simulated thermomechanical processing, Metal 2001, Ostrava, Czech Republic (2001).

[3] P. Suikkanen, Development and Processing of Low Carbon Bainitic Steels, Academic dissertation, Acta Univ. Oul., OulunYliopisto, Oulu 2009.

[4] API Specification 5L: Specification for Linepipe, ISO 3183:2007 (Modified), petroleum and natural gas industries-Steel pipe for pipeline transportation systems, forty-fourth edition, October 2007

[5] I. Tamura, H Sekine., T. Tanaka, C.Ouchi, Thermomechanical Processing of High-Strength Low-Alloy Steels, Butterworth \& Co. Ltd., London, 1988.

[6] B.P. Wynne, P. Cizek, C.H.J. Davies, B.C. Muddle, P.D. Hodgson, Effects of processing parameters on the mechanical properties of low-carbon microalloyed steels, In Proc. Int. Conf. THERMEC`97. Warrendale, USA: TMS, 1997, 837-843.

[7] M. Soliman, H. Palkowski, Influence of hot working parameters on microstructure evolution, tensile behavior and strain aging potential of bainitic pipeline steel, Materials \& Design 87 (2015) $450-465$.

[8] M. Gomez, P. Valles, S.F. Medina, Evolution of microstructure and precipitation state during thermomechanical processing of a X80 microalloyed steel, Materials Science and Engineering, 2011, Vol. A 528, 4761-4773. 